\title{
Determination of Nitrobenzene in Water and Ice Samples Collected from the Songhua River after an Explosion of a Petrochemical Plant and Investigation on Enclosing Behavior of Nitrobenzene into Ice
}

\author{
Yingjie DaI, ${ }^{* 1}$ Norifumi TeruI, ${ }^{2}$ Yongbo Lin, ${ }^{* 3}$ Shunitz Tanaka, ${ }^{* 1 \dagger}$ Kazuo Jin, ${ }^{* 4}$ Yuji Hirama, ${ }^{* 4}$ \\ Masahiro Teduka, ${ }^{* 5}$ Milin Zhang, ${ }^{* 6}$ Xiande Shen, ${ }^{* 7}$ and Bunshi Fugetsu ${ }^{* 1}$ \\ *1 Graduate School of Environmental Earth Science, Hokkaido University, Sapporo 060-0810, Japan \\ *2 Ichinoseki National College of Technology, Takanashi, Hagisho, Ichinoseki 021-8511, Japan \\ *3 School of Forestry, Northeast Forestry University, No. 26 Hexing Road, Harbin 150040, P. R. China \\ *4 Hokkaido Institute of Public Health, N19, W12, Kita, Sapporo 060-0819, Japan \\ *5 Resource and Energy Department, Hokkaido Industrial Research Institute, N19, W12, Kita, \\ Sapporo 060-0819, Japan \\ *6 Key Laboratory of Super-light Materials \& Surface Technology, Ministry of Education, \\ Harbin Engineering University, No.145 Nantong Street, Harbin 150001, P. R. China \\ *7 College of Materials Science and Chemical Engineering, Harbin Engineering University, \\ No.145 Nantong Street, Harbin 150001, P. R. China
}

\begin{abstract}
In this study, nitrobenzene in water and ice samples collected from the Songhua River after the explosion of a petrochemical plant was determined by GC/MS. The results showed that nitrobenzene was detected in most of the water and ice samples taken from the Songhua River. However, the concentration of nitrobenzene in all water and ice samples was from 0 to $0.65 \mu \mathrm{g} \mathrm{L}^{-1}$; this range was sufficiently lower than the permissible level $\left(0.017 \mathrm{mg} \mathrm{L}^{-1}\right)$ for drinking water in China. The enclosing behavior of nitrobenzene in ice was also investigated. The amount of nitrobenzene enclosed in ice was lower than that reported by UNEP.
\end{abstract}

(Received January 1, 2010; Accepted March 10, 2010; Published April 10, 2010)

\section{Introduction}

An explosion occurred at a petrochemical plant owned by Petro China Jilin Petrochemical Company in Jilin, Jilin Province, China, on 13 November 2005. Information from various media indicated that the explosion had resulted in a spill of approximately 100 tons of chemicals, including benzene, aniline and nitrobenzene (NB), into the Songhua River. ${ }^{1-3}$ Five people died, and more than seventy others were injured by the explosion. ${ }^{4}$ Consequently, the main supply of drinking water of Harbin city (population nearly four million), on the banks of the Songhua River, was cut off for several days so as to avoid any contamination of the water distribution systems in Harbin. ${ }^{5}$ The Songhua River $(1927 \mathrm{~km})$, which flows through Jilin and Heilongjiang provinces, merges with the Heilongjiang River (called the Amur River in Russia) and forms a national border with Russia, and eventually flows into the Sea of Okhotsk. ${ }^{6}$

The pollutants spilled from the explosion were reported to be benzene, aniline and NB. However, the concentration of benzene was immediately reduced to the permissible level $\left(0.01 \mathrm{mg} \mathrm{L}^{-1}\right)$ in surface water in China, and aniline was not detected. ${ }^{7} \mathrm{NB}$ was a main pollutant to spread to a wide area in the Songhua River. ${ }^{8}$ NB is widely used in the field of chemical industry for the production of raw materials, such as aniline,

† To whom correspondence should be addressed.

E-mail: shunitz@ees.hokudai.ac.jp quinoline, azobenzene and trinitrotoluene, which are used to make explosives, rubbers, pesticides, agricultural chemicals and so on. In fact, NB has been classified as a pollutant of major concern. ${ }^{9,10}$ Exposure to NB via inhalation or absorption through the skin causes methemoglobinemia, which results in fatigue, dizziness, headache and nausea. ${ }^{11} \mathrm{NB}$ is one of the aromatic compounds that remain in the environment for a relatively long period. The specific gravity of NB is greater $\left(1.2 \mathrm{~g} \mathrm{~cm}^{-3}\right.$ at $\left.4^{\circ} \mathrm{C}\right)$ than that of water, and it has a high boiling point $\left(210.8^{\circ} \mathrm{C}\right) .^{12,13}$ Therefore, when released into an aqueous environment, NB tends to sink to the bottom of water, where it remains for a long time. On the other hand, the solubility of $\mathrm{NB}$ in water is relatively high $\left(1900 \mathrm{mg} \mathrm{L}^{-1}\right.$ at $\left.20^{\circ} \mathrm{C}\right)$. When it is released into rivers, it is gradually hydrated and partially dissolved in water. ${ }^{14}$

Some studies of NB in water, fishes, and sediment samples collected from the Songhua River after passing of contaminants have been reported. ${ }^{5,15-18}$ Among them, Liu et al. predicted the aquatic ecological impact of NB and Tanaka et al. determined NB in fish samples collected from the Songhua River. ${ }^{5,15,16}$ Lei et al. evaluated the adsorption behavior of NB that spilled onto sediments along the Songhua River. ${ }^{17}$ Zhu et al. studied the transport and fate of NB in the river water body. ${ }^{18}$ However, few investigations of NB in water and ice samples collected from the Songhua River after the explosion of the petrochemical plant had been reported. Although the concentration of NB in river water has now decreased to a safe level, we still have to pay much attention to the case of the Songhua River, because 


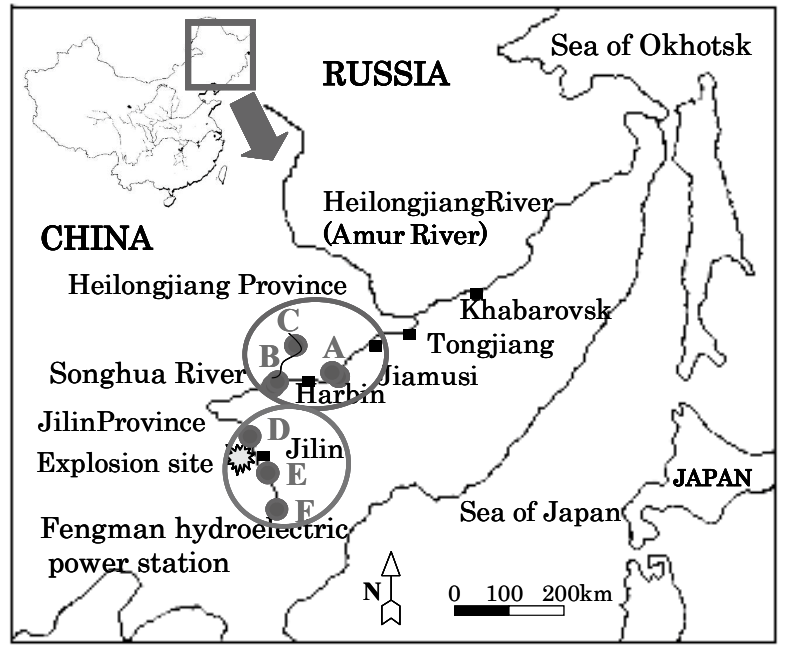

Fig. 1 Map for the sampling sites near the Songhua River. A, Downstream; B, upper stream; C, branch in Harbin; D, downstream; E, upper stream; F, Fengman hydroelectric power station in Jilin.

pollution by accidents such as an explosion, may cause in the future severe damage to human health and the aquatic ecosystem in not only China, but also in all other countries of the world. ${ }^{19}$ In order to understand the total picture of the pollution in the Songhua River, it is important to analyze NB not only in water and ice samples, but also fish and sediment samples in the river. We have collected and determined NB in fish and sediment samples from the Songhua River in Harbin city after the passing of contaminants, as well as water and ice samples. The results of NB in fish samples have been reported. ${ }^{15}$ In this study, we focused on the determination of NB in water and ice samples, and also the entrapping behavior of NB in ice, because it is important to know the pollution situation in order to consider the secondary pollution with NB eluted from ice.

\section{Experimental}

\section{Reagents and apparatus}

NB used for the standard solution was purchased from Wako Pure Chemicals Co. (Osaka, Japan). NB- $d_{5}$, used as an internal standard, was from MSD Isotopes (Montreal, Canada). Hexane, acetone, anhydrous sodium sulfate and the other reagents used in this study were of commercially available special grade from Wako Pure Chemicals. The water used in this study was double-distilled water. The concentration of NB was analyzed by GC/MS (Shimadzu GC/MS QP5050A, Kyoto, Japan). The GC conditions were as follows: capillary column, DB-5 (J\&W Scientific, CA, USA); $30 \mathrm{~m} \times 0.25 \mathrm{~mm}$ i.d., $0.15 \mu \mathrm{L}$ film thickness. The initial temperature was $60^{\circ} \mathrm{C}$ for $2 \mathrm{~min}$. The temperature was then increased to $140^{\circ} \mathrm{C}$ at a rate of $10^{\circ} \mathrm{C} \mathrm{m^{-1 }}$ and to $280^{\circ} \mathrm{C}$ at a rate of $20^{\circ} \mathrm{C} \mathrm{min}^{-1}$. Helium, used as a carrier gas, was controlled at a flow rate of $1.7 \mathrm{~mL} \mathrm{~min}^{-1}$ in a constant-flow mode. The injection temperature was $200^{\circ} \mathrm{C}$, and the detector temperature was $280^{\circ} \mathrm{C}$. The sample injection volume was $2 \mu \mathrm{L}$. The mass spectrometer was operated in a selected ion monitoring mode, and the electron multiplier voltage was set at $1300 \mathrm{eV}$ with an ion source temperature of $280^{\circ} \mathrm{C}$. A water sampler WB-SS (Pulite Technology Co., Ltd., Beijing, China) was used for taking water samples.

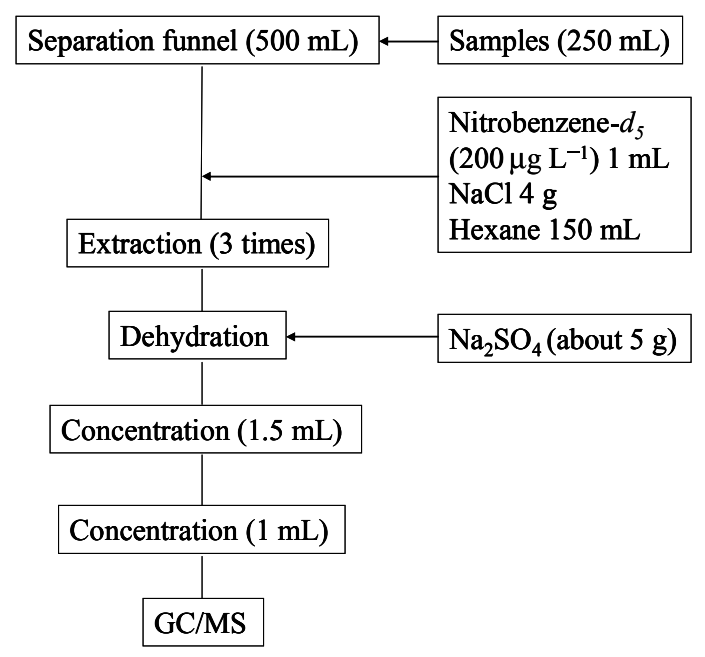

Fig. 2 Flow chart for the analytical procedure of NB in water and ice samples.

\section{Sampling}

The ice and water samples were collected from the city of Harbin and Jilin on the Songhua River, in March, May and October of 2006 and March of 2009. The sampling sites included A (downstream), B (upper stream), C (branch) in Harbin and D (downstream), E (upper stream), F (Fengman hydroelectric power station) in Jilin (see Fig. 1). Harbin is around $600 \mathrm{~km}$ downstream of the explosion site. In March of 2006 the thickness of ice in the Songhua River was about $1-1.5 \mathrm{~m}$ at $\mathrm{A}$ site in the city of Harbin. The ice samples were taken from the surface $(0 \mathrm{~m})$, the middle $(0.2 \mathrm{~m})$ and the near bottom $(1 \mathrm{~m})$ of the ice layer by a pickax. On the other hand, at site B in the city of Harbin, we could not find out the ice layer in the center of the river, so we could take only the surface ice remaining or the shore of the Songhua River.

Water samples were taken from the surface and $5 \mathrm{~m}$ depth in the river by a water sampler. The samples were preserved in an air-tight condition under cold temperature during sampling, and were then kept in the dark at $4^{\circ} \mathrm{C}$ after being transported to the laboratory. The water samples (after melting of ice) were kept in glass bottles.

\section{Analytical procedure}

The procedure for determining of the NB in water and ice samples is outlined in Fig. 2. After washing a $500-\mathrm{mL}$ separation funnel with $20 \mathrm{~mL}$ of hexane, a $250-\mathrm{mL}$ portion of the water or ice sample was put into there. The surrogate standard $\left(200 \mu \mathrm{g} \mathrm{L}^{-1} \mathrm{NB}-d_{5}\right.$-acetone solution, $\left.1 \mathrm{~mL}\right)$ and $4 \mathrm{~g}$ of $\mathrm{NaCl}$ were added to a $250-\mathrm{mL}$ sample solution. The sample was extracted 3 times with $50 \mathrm{~mL}$ of hexane, and the organic phases were combined and then dehydrated by passing through anhydrous $\mathrm{Na}_{2} \mathrm{SO}_{4}$ (about $5 \mathrm{~g}$ ). The organic phase was concentrated to $1.5 \mathrm{~mL}$ by a vacuum evaporation method, and further evaporated to $1 \mathrm{~mL}$ under a nitrogen stream. The aliquot was analyzed by GC/MS. The experiment was repeated three times for each condition, and the average values were calculated. The relative standard deviation for the determination of NB by this method was approximately $5 \%$. The detection limit of the $\mathrm{NB}$ in water was $0.01 \mu \mathrm{g} \mathrm{L}^{-1}$. The recoveries from the Songhua River's water samples were $106 \%$. 
Table 1 Concentration of NB in the water samples collected from the Songhua River

\begin{tabular}{|c|c|c|}
\hline $\begin{array}{l}\text { Collection } \\
\text { date }\end{array}$ & Site & $\begin{array}{c}\text { Concentration of } \\
\mathrm{NB} / \mu \mathrm{g} \mathrm{L}^{-1}\end{array}$ \\
\hline \multirow[t]{2}{*}{ March, 06} & Harbin A (downstream) & 0.19 \\
\hline & Harbin B (upper stream) & 0.03 \\
\hline \multirow[t]{2}{*}{ May, 06} & Harbin A (downstream) & 0.03 \\
\hline & Harbin B (upper stream) & 0.03 \\
\hline \multirow[t]{6}{*}{ October, 06} & Harbin A (downstream) & 0.04 \\
\hline & Harbin B (upper stream) & 0.04 \\
\hline & Harbin C (branch) & 0.02 \\
\hline & Jilin D (downstream) & Not detected ${ }^{\mathrm{a}}$ \\
\hline & Jilin E (upper stream) & 0.05 \\
\hline & $\begin{array}{l}\text { Jilin F (Fengman hydroelectric } \\
\text { power station) }\end{array}$ & 0.11 \\
\hline
\end{tabular}

a. The detection limit of the nitrobenzene in water is $0.01 \mu \mathrm{g} \mathrm{L}^{-1}$.

\section{Procedure to investigate the enclosing behavior of $N B$ in ice}

The enclosing behavior of NB in ice was investigated as follows: $250 \mathrm{~mL}$ of $\mathrm{NB}$ solution ( 1 to $10 \mathrm{mg} \mathrm{L}^{-1}$ ) was introduced into a $300-\mathrm{mL}$ tall beaker, whose side and bottom were surrounded with a polyurethane sheet (thickness, $2 \mathrm{~cm}$ ), and the beaker was settled in a freezing cabinet at -10 to $-30^{\circ} \mathrm{C}$, while the solution of NB was stirred at the bottom of the beaker using a magnetic stirrer. When half of the NB solution from the top was frozen, the ice, whose thickness was about $4 \mathrm{~cm}$, was picked up and cut by a saw at every $1 \mathrm{~cm}$ from the top. After melting all pieces of ice, the concentration of NB in the solution was analyzed by GC/MS.

\section{Results and Discussion}

\section{Concentration of NB in water and ice samples from the Songhua} River

The date when the explosion occurred in Jilin was 13 November 2005, and the date when the pollution plume arrived at Harbin city was 25 November 2005. It was said that because it was the beginning of the winter season, the surface of the Songhua River had begun to freeze, and some amount of the NB might have been captured in the ice. According to the UNEP's report, the concentration of NB in an ice sample was one fourth of that in water. ${ }^{20}$ It was in the middle of March of 2006 that we at first took the ice and water samples from the Songhua River in the city of Harbin. This was four months later after the spill of NB to the river. In the case of the Songhua River having a massive flow of $2350 \mathrm{~m}^{3} \mathrm{~s}^{-1}$, four months were sufficient for washing up the pollution sites. ${ }^{6}$ It was predicted that the pollution level with NB was very low around Harbin city at that time. The analytical data of ice and water samples collected from the Songhua River are given in Tables 1 and 2.

Table 1 shows that the NB concentrations in water samples were 0.025 to $0.19 \mu \mathrm{g} \mathrm{L}^{-1}$. The concentration was much lower than the concentration $\left(0.58 \mathrm{mg} \mathrm{L}^{-1}\right)$ of $\mathrm{NB}$ in the pollution plume that arrived at Harbin city on 25 November 2005. After passing away the pollution plume to the downstream, the concentration of NB in the river water decreased rapidly due to water dilution, volatilization, decomposition, deposition on sediments and living bodies and so on..$^{21,22}$ Moreover, it was said that plenty of water from the Fengman hydroelectric power station was released into the river in order to dilute the pollutants. However, there was little information on the amount of water
Table 2 Concentration of NB in the ice samples collected from the Songhua River in Harbin

\begin{tabular}{clc}
\hline $\begin{array}{c}\text { Collection } \\
\text { date }\end{array}$ & \multicolumn{1}{c}{ Site } & $\begin{array}{c}\text { Concentration of } \\
\mathrm{NB} / \mu \mathrm{g} \mathrm{L}^{-1}\end{array}$ \\
\hline March, 06 & B (near surface) & 0.65 \\
& B (surface) & 0.04 \\
& B (0.2 m below the surface) & 0.03 \\
& B (1 m below the surface) & 0.05 \\
March, 09 & A (surface) & 0.02 \\
& A (0.2 m below the surface) & 0.08 \\
& B $(0.2 \mathrm{~m}$ below the surface) & 0.04 \\
& C $(0.2 \mathrm{~m}$ below the surface) & 0.10 \\
\hline
\end{tabular}

released.

On the other hand, the concentrations of NB in ice samples were also sufficiently low, except for the value of one ice sample near the surface $\left(0.65 \mu \mathrm{g} \mathrm{L}^{-1}\right)$, as shown in Table 2. If the ice was formed just while the pollution plume was passing through point $\mathrm{B}$ in Harbin city, and if the concentration of NB in the ice became one fourth of that in water $\left(0.58 \mathrm{mg} \mathrm{L}^{-1}\right)$, as described in UNEP's report, then the concentration of NB in the ice might have been about $0.15 \mathrm{mg} \mathrm{L}^{-1}$. However, the concentration of NB in the ice samples was much lower than that value. Some possible reasons could be thought to explain the difference between the concentration of NB in the ice samples and the predicated one. One was due to the fact that the surface water of the Songhua River in Harbin city was frozen after passing away of the pollution plume. The second was that, when ice was formed, there was a special process for excluding NB from the ice. Therefore, the freezing process of water containing NB is considered in the next section.

\section{Investigation of the enclosing behavior of $\mathrm{NB}$ into ice}

The maximum concentration of NB in the pollution plume at Harbin was reported to be $0.58 \mathrm{mg} \mathrm{L}^{-1}$, which was about 33-times the permissible level for drinking water $\left(0.017 \mathrm{mg} \mathrm{L}^{-1}\right)$ in China. ${ }^{23}$ The concentration of NB when the pollution plume passed through Jiamusi on 8 December 2005 was $0.17 \mathrm{mg} \mathrm{L}^{-1}$. It was said that the surface of the Songhua River in those days had begun to freeze, and some NB in the river water was captured into the ice. However, the concentration of NB in the ice samples taken in March of 2006 at Harbin was very low. Therefore, the enclosing behavior of NB into ice was investigated by using $250 \mathrm{~mL}$ of $\mathrm{NB}$ solution $\left(1,5\right.$ and $\left.10 \mathrm{mg} \mathrm{L}^{-1}\right)$ in order to clarify the effect of the NB concentration in water on the enclosing behavior of NB into ice. Among them, $1 \mathrm{mg} \mathrm{L}^{-1}$ was close to the concentration of NB in the pollution plume that arrived at Harbin city. After freezing half of the solution at $-20^{\circ} \mathrm{C}$, the ice was divided at every $1 \mathrm{~cm}$ from the top. Figure 3 shows the concentration of NB in each part of the ice. The concentration of NB in the surface ice (0 to $1 \mathrm{~cm}$ ) using 1,5 and $10 \mathrm{mg} \mathrm{L}^{-1} \mathrm{NB}$ solutions were $0.08,0.37$ and $0.63 \mathrm{mg} \mathrm{L}^{-1}$, respectively, and the concentration of $\mathrm{NB}$ in ice was about one twelfth of that in solution, independent of the concentration of the solution.

The lower was the ice layer the higher was the concentration of NB found in the ice layer. This was due to an increase in the concentration of NB in the solution, as a result of the exclusion of NB from ice crystals to the solution when water was frozen. During passing through of the pollution plume in the Songhua River, the temperatures in Jiamusi and Harbin were in the range between -10 and $-14^{\circ} \mathrm{C}$ during daytime, and between -21 and 


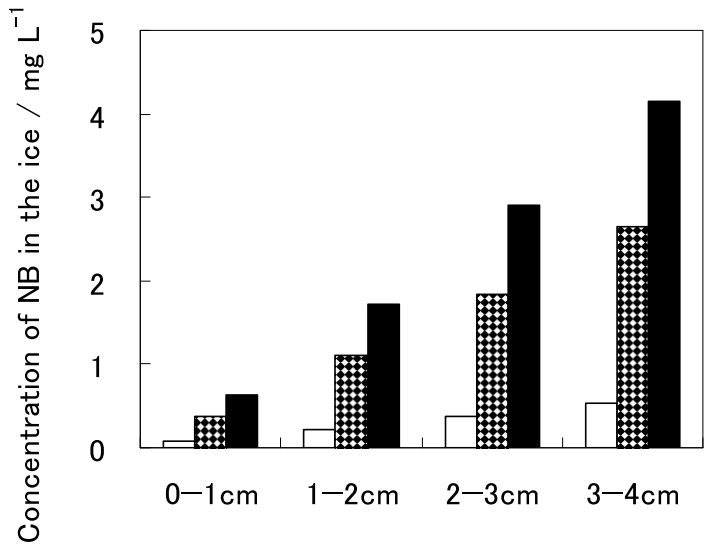

Fig. 3 Enclosure of $\mathrm{NB}$ into ice: $250 \mathrm{~mL}$ of $\mathrm{NB}$ solution. $\square$, $1 \mathrm{mg} \mathrm{L}^{-1}$; $5 \mathrm{mg} \mathrm{L}^{-1} ; \mathbf{\square}, 10 \mathrm{mg} \mathrm{L}^{-1}$, was frozen at $-20^{\circ} \mathrm{C}$ with a stirring speed of $250 \mathrm{rpm}$.

$-23^{\circ} \mathrm{C}$ at night. ${ }^{20}$ The effect of the temperature on the enclosing behavior of $\mathrm{NB}$ in ice was investigated by using $250 \mathrm{~mL}$ of an NB solution $\left(10 \mathrm{mg} \mathrm{L}^{-1}\right)$. The results showed that the concentration of NB in the ice samples increased with decreasing the temperatures as shown in Fig. 4. The effect of stirring on the enclosing behavior of $\mathrm{NB}$ was also investigated; $250 \mathrm{~mL}$ of an NB solution $\left(10 \mathrm{mg} \mathrm{L}^{-1}\right)$ was frozen at $-20^{\circ} \mathrm{C}$ with a stirring speed of 0 and $250 \mathrm{rpm}$. The concentration of NB in ice samples without stirring was slightly larger than that at $250 \mathrm{rpm}$.

The ice-forming process normally tends to exclude every substance other than the water molecules from ice crystal. Therefore, most solutes were to be moved into the liquid phase from ice crystals during the ice-forming process, and were concentrated there. When the solute between the ice crystals was further concentrated, the freezing point of the solution was decreased. This prevented the solution from freezing until at a lower temperature. Meanwhile, ice crystal grew slowly to a larger size when the temperature was closer to the freezing point. However, when the temperature was much lower than the freezing point, the rate of ice growth became faster than the rate of exclusion of the solute, and crystal nucleation occurred in the whole solution. Consequently, greater amount of the solute was incorporated among the ice crystals. The results shown in Figs. 3 and 4 could be explained by the reasons described above.

The ratio of the concentration of NB in the ice to that of solutions (about one twelfth) obtained by our experiments differed from that reported by UNEP (one fourth). In the UNEP's report, the sampling site and the depth of the tested ice were not clarified. Therefore, it was impossible to compare the data obtained in our laboratory with that from an actual sample. The not-constant temperature at the actual site, the effect of the climate, such as the wind and pressure, precipitates like snow and rain, the heterogeneity in water flow, and many other factors seem to have brought about a large difference in the NB concentration in the ice. In a closed system like in this experiment, NB was concentrated in water during the ice-forming process. However, in the river, NB might not be concentrated because NB excluded from ice crystal was flowed to downstream. In any condition, the concentration of NB in the surface ice was about one twelfth that of water. However, the concentration of $\mathrm{NB}$ in the actual ice samples was much lower (one thousandth) than one twelfth of $0.58 \mathrm{mg} \mathrm{L}^{-1}$. The concentration could not be explained only by the exclusion of NB from ice.

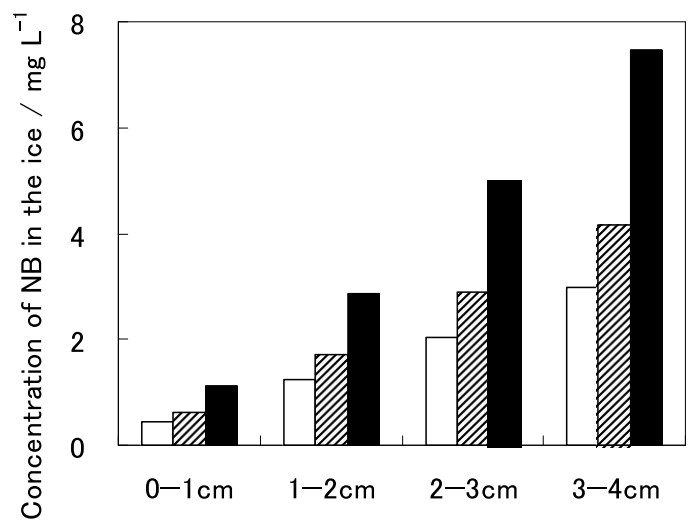

Fig. 4 Effect of temperature for $\square,-10^{\circ} \mathrm{C} ; \mathbb{Z},-20^{\circ} \mathrm{C} ; \mathbf{\square},-30^{\circ} \mathrm{C}$ on enclosing NB into ice: $250 \mathrm{~mL}$ of NB solution $\left(10 \mathrm{mg} \mathrm{L}^{-1}\right)$ was frozen with a stirring speed of $250 \mathrm{rpm}$.

\section{Conclusions}

In this study, the concentration of NB in water and ice samples collected from the Songhua River was determined by GC/MS. The enclosing behavior of NB in ice was also investigated. NB was detected in most of the water and ice samples taken in the Songhua River. However, the concentration of NB in any water samples was sufficiently low. The concentration of NB in ice was also very low in spite of the ice formed during the winter season of the accident. It was thus though that the water in the Songhua River at Harbin was frozen after passing away of the pollution plume.

The possibility of secondary pollution of the river with NB eluted from ice was of concern. However, from our results, the amount of NB eluted from ice was very low, and then secondary pollution with NB in the spring season might not have occurred near Harbin city.

\section{Acknowledgements}

The present work was supported by YUASA International Foundation, and also partly supported by Global COE Program "Establishment of Center for Integrated Field Environmental Science" at Hokkaido University.

\section{References}

1. D. Li, M. Yang, Z. Li, R. Qi, J. He, and H. Liu, FEMS Microbiol. Ecol., 2008, 65, 494.

2. Z. L. Li, M. Yang, D. Li, R. Qi, H. J. Liu, J. F. Sun, and J. H. Qu, J. Environ. Sci., 2008, 20, 778.

3. Y. Dai, Y. Mihara, S. Tanaka, K. Watanabe, and N. Terui, J. Hazard. Mater., 2010, 174, 776.

4. F. Tan, Asian Chem. News, 2005, 11, 11.

5. R. Liu, H. Liu, D. Wan, and M. Yang, J. Environ. Sci., 2008, 20, 796.

6. S. Nagahora, T. Akutagawa, K. Murata, T. Nakajima, N. Z. Song, and P. Y. Zhai, J. Jpn. Soc. Water Environ., 2007, 30, 101.

7. R. Atkinson, Journal of Physical and Chemical Reference Data, Monograph No. 1, 1989. 
8. Database of the Main Component was Nitrobenzene, Compilation prepared by Heilongjiang Information Network of China (HINC), http://www.hljxxw.gov.cn/sqgl/ dxqh/t20051115_3204.htm/.

9. W. H. O., Environmental Health Criteria 230, Nitrobenzene, 2003, Geneva.

10. X. K. Zhao, G. P. Yang, and X. C. Gao, Chemosphere, 2003, 52, 917.

11. M. Ikeda and A. Kita, Br. J. Ind. Med., 1964, 21, 210.

12. T. Jarusuwannapoom, W. Hongrojjanawiwat, S. Jitjaicham, L. Wannatong, M. Nithitanakul, C. Pattamaprom, P. Koombhongse, R. Rangkupan, and P. Supaphol, Eur. Polym. J., 2005, 41, 409.

13. M. S. Simmons and R. G. Zepp, Water Res., 1986, $20,899$.

14. F. Villacañas, M. F. R. Pereira, J. J. M. Órfão, and J. L. Figueiredo, J. Colloid Interface Sci., 2006, 293, 128.

15. E. Tanaka, Y. Dai, Y. Lin, B. Fugetsu, S. Tanaka, K. Jin, and Y. Hirama, Bunseki Kagaku, 2009, 58, 807.

16. E. Tanaka, Y. Dai, S. Tanaka, K. Jin, B. Fugetsu, and Y. Lin, in Proceedings of 16th Symposium on Environmental Chemistry, 2007, Kitakyushu, Japan, 646 - 647.

17. B. Lei, S. Huang, M. Qiao, T. Li, and Z. Wang, J. Environ. Sci., 2008, 20, 769.

18. L. Y. Zhu, B. L. Ma, L. Zhang, and L. Zhang, Chemosphere, 2007, 69, 1579.

19. K. Jin, Y. Hirama, S. Kobayashi, M. Chiba, Y. Itoh, Y. Lin, B. Fugetsu, and S. Tanaka, in Proceedings of 55th on the Japan Society for Analytical Chemistry, 2006, Osaka, Japan, 370 - 371.

20. United Nations Environment Program (U. N. E. P.), The Songhua River Spill China, Field Mission Report, 2005.

21. SEPA news release, http://english.sepa.gov.cn/zwxx/xwfb/ index_3.htm.

22. X. Wang, Y. Li, Y. Wang, T. Wang, Q. Gao, and X. Du, J. Hazard. Mater., 2009, 172, 755.

23. W. Fu, H. Fu, K. Skøtt, and M. Yang, Environ. Sci. Pollut. Res., 2008, 15, 178. 